\title{
METHODS OF PROTEIN SEPARATION
}

Volume 2 


\section{BIOLOGICAL SEPARATIONS}

\section{Series Editor: Nicholas Catsimpoolas Massachusetts Institute of Technology Cambridge, Massachusetts}

Methods of Protein Separation, Volume 1

Edited by Nicholas Catsimpoolas $\bullet 1975$

Methods of Protein Separation, Volume 2

Edited by Nicholas Catsimpoolas $\bullet 1976$

A Continuation Order Plan is available for this series. A continuation order will bring delivery of each new volume immediately upon publication. Volumes are billed only upon actual shipment. For further information please contact the publisher. 

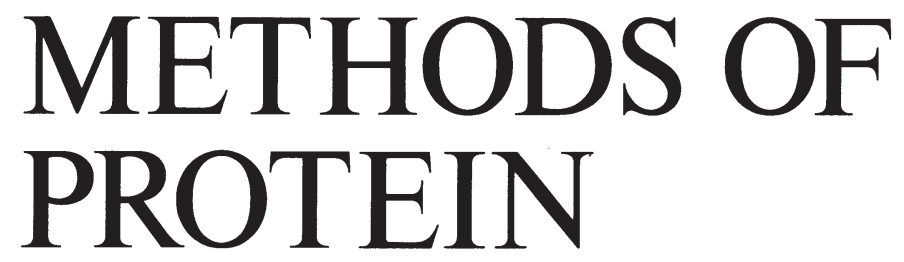

SEPARATION

\section{Volume 2}

Edited by

Nicholas Catsimpoolas

Massachusetts Institute of Technology

Cambridge, Massachusetts 
Library of Congress Cataloging in Publication Data

Main entry under title:

Methods of protein separation.

(Biological separations)

Includes bibliographies and index.

1. Proteins. 2. Separation (Technology) 3. Biological chemistry. I. Catsimpoolas, Nicholas. II. Series.

QD431.M47

$574.1^{\prime} 9245^{\prime} 028$

$75-17684$

ISBN 978-1-4684-9986-5

ISBN 978-1-4684-9984-1 (eBook)

DOI 10.1007/978-1-4684-9984-1

C1976 Springer Science+Business Media New York

Originally published by Plenum Press, New York in 1976.

Softcover reprint of the hardcover 1st edition 1976

No part of this book may be reproduced, stored in a retrieval system, or transmitted, in any form or by any means, electronic, mechanical, photocopying, microfilming, recording, or otherwise, without written permission from the Publisher 


\section{CONTRIBUTORS}

Gary K. Ackers, Department of Biochemistry, University of Virginia, Charlottesville, Virginia 22901

Andreas Chrambach, Reproduction Research Branch, National Institute of Child Health and Human Development, National Institutes of Health, Bethesda, Maryland 20014

Stellan Hjertén, Institute of Biochemistry, Biomedical Center, University of Uppsala, Uppsala, Sweden

Barend H. J. Hofstee, Biochemistry Division, Palo Alto Medical Research Foundation, Palo Alto, California 94301

Thomas M. Jovin, Department of Molecular Biology, Max-Planck Institute for Biophysical Chemistry, Goettingen, German Federal Republic

Leslie H. Kirkegaard, Biological Products Department, Litton Bionetics, Inc., Kensington, Maryland 20795

David Rodbard, Reproduction Research Branch, National Institute of Child Health and Human Development, National Institutes of Health, Bethesda, Maryland 20014

P. Just Svendsen, The Protein Laboratory, University of Copenhagen, Copenhagen, Denmark 


\section{PREFACE}

This open-end treatise on methods concerning protein separation had its beginning in an American Chemical Society symposium entitled "Contemporary Protein Separation Methods" which was held in Atlantic City, New Jersey in September 1974. The purpose of the symposium-and subsequently of the present work-was to review the available modern techniques and underlying principles for achieving one of the very important tasks of experimental biology, namely the separation and characterization of proteins present in complex biological mixtures. Physicochemical characterization was covered only as related to the parent method of fractionation and therefore involved mostly mass transport processes. Additionally, the presentation of methods for gaining insight into complex interacting protein profiles was considered of paramount importance in the interpretation of separation patterns. Finally, specific categories of proteins (e.g., chemically modified, deriving from a specific tissue, conjugated to different moieties, etc.) require meticulous trial and selection and/or modification of existing methodology to carry out the desired separation. In such cases, the gained experience provides valuable guidelines for further experimentation.

Although powerful techniques exist today for the separation and related physicochemical characterization of proteins, many biological fractionation problems require further innovations. It is hoped that the description in the present treatise of some of the available separation tools and their limitations will provide the necessary integrated background for new developments in this area.

Cambridge, Massachusetts

Nicholas Catsimpoolas 


\section{CONTENTS}

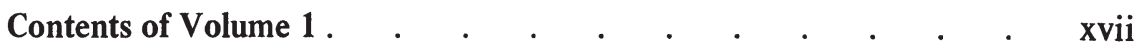

\section{Chapter 1}

\section{Scanning Gel Chromatography}

Gary K. Ackers

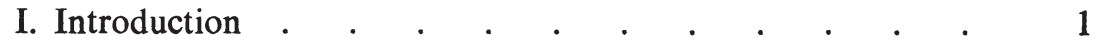

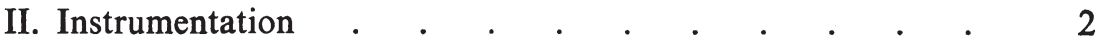

A. Scanning Gel Chromatographs: General Description . 2

B. Optical and Photometric Requirements . . . . 4

III. Experimental Parameters . . . . . . . . $\quad$. 6

A. Partition Cross Sections and Partition Coefficients . . 6

B. Small-Zone Transport . . . . . . . . . . 9

C. Large-Zone Transport . . . . . . . . . 10

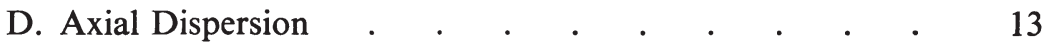

E. Equilibrium Saturation Method . . . . . . 16

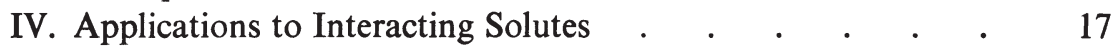

A. Protein Subunit Interactions . . . . . . . 17

B. Macromolecule Ligand Binding . . . . . . 20

C. Active Enzyme Transport . . . . . . . . . 21

V. Concluding Remarks . . . . . . . . . . . . 24

VI. References . . . . . . . . . . . . . . $\quad$. 25 
Chapter 2

Analytical and Preparative Polyacrylamide Gel Electrophoresis : An Objectively Defined Fractionation Route, Apparatus, and Procedures

A. Chrambach, T. M. Jovin, P. J. Svendsen, and D. Rodbard

I. Concept of an "Objectively Defined Fractionation Route" . 27

A. "Quantitative" Fractionation . . . . . . 27

B. Choice of Polyacrylamide Gel Electrophoresis . . . 29

C. Preparative-Scale Fractionation . . . . . . . 29

II. Optimization of the $\mathrm{pH}$ of PAGE $\quad$. $\quad . \quad$. $\quad . \quad$. $\quad$. 31

A. Charge Fractionation . . . . . . . . . . 31

B. Stacking in Multiphasic Zone Electrophoresis . . . 32

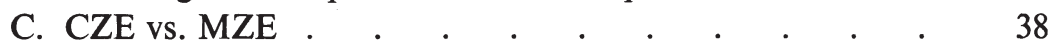

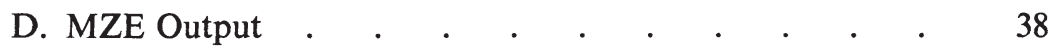

E. Procedure of Selection of Operative $\mathrm{pH}$ and Selective Stacking Limits . . . . . . . . . . . . . 41

1. Polarity and Temperature . . . . . . . . . 41

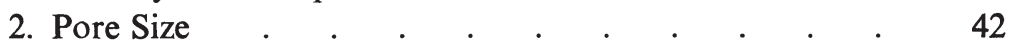

3. The MZE Systems Catalog _ . . . . . . . 43

4. Ionic Strength $\quad . \quad$. . . . . . . . . . . 44

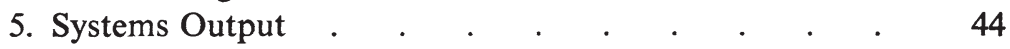

6. Stability Test . . . . . . . . . . . . . 45

7. Experimental Optimization _ . . . . . . . . 46

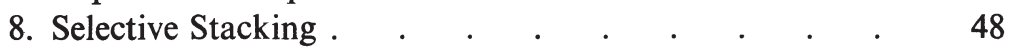

III. Determination of Reproducible $R_{f}-\% T$ Sets: $R_{f}$ as a Physical Constant . . . . . . . . . . . . . . . 49

A. Control of Polymerization _. . . . $\quad . \quad$. $\quad . \quad$. 52

1. Choice, Purification, and Stoichiometric Use of Monomers of Polyacrylamide . $\quad . \quad$. $\quad . \quad$. $\quad . \quad$. 52

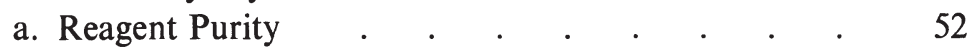

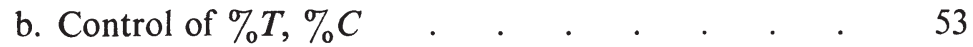

2. Free Radical and Redox Conditions . . . . . 53

a. Initiators . . . . . . . . . . . . . 54

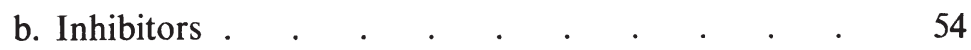

c. Redox . . . . . . . . . . . . . 55

3. Polymerization Solvent $\quad . \quad$. $\quad . \quad$. $\quad . \quad$. $\quad$. 55

4. Temperature . . . . . . . . . . . . . 56

5. Polymer Geometry and Temporal Stability . . . $\quad 56$

6. Rate of Polymerization . . . . . . . . . 57

7. Procedure of Polymerization of Cylindrical Gels . . 58 
8. Procedure of Polymerization of One-Dimensional Vertical Gel Slab. . . . . . . . . . . . . . 61

B. Control of Electrophoresis . . . . . . . . . . . 61

1. Solvent . . . . . . . . . . . . . . . 61

a. Buffer . . . . . . . . . . . . . 61

b. Ionic Solutes . . . . . . . . . . . . $\quad$. 62

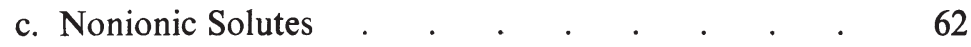

d. Preelectrophoresis . . . . . . . . . . 63

2. Joule Heating . . . . . . . . . . 63

3. Procedure of Electrophoresis . . . . . . . . $\quad 65$

a. Load . . . . . . . . . . . . 65

b. Procedure for Cylindrical Gels . . . . . 65

c. Procedure of Electrophoresis on the Partitioned Gel Slab. . . . . . . . . . . 66

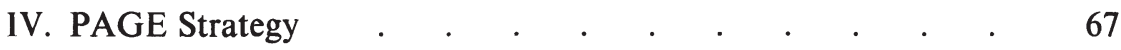

A. Computer Programs (PAGE-PACK) . . . . . . 67

B. Ferguson Plot . . . . . . . . . . . . . . 67

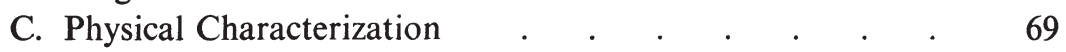

1. Molecular Weight, Valence . . . . . . . 69

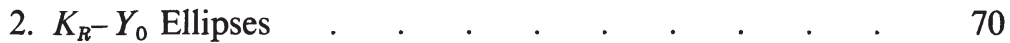

3. SDS-PAGE . . . . . . . . . . . 71

D. $T_{\text {opt }}$ : Optimization of Gel Concentration . . . . 72

E. Charge Fractionation . . . . . . . . . . . 72

F. Macromolecular Mapping . . . . . . . . 73

G. Preparative-Scale PAGE . . . . . . . . . 74

V. Apparatus, Computer Programs, and Procedures . . . 75

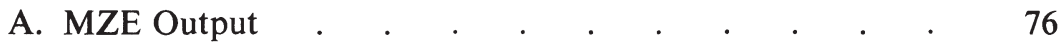

B. Analytical PAGE Accessory . . . . . . . . . . 78

1. Analytical PAGE Apparatus . . . . . . . 78

a. Tube and Vertical Slab Apparatus . . . . . 78

Temperature Control . . . . . . . . . 78

Versatile Load Capacity $\quad$. $\quad . \quad$. $\quad$. $\quad . \quad$. 79

An Interchangeable Upper Buffer Reservoir for a Vertical Gel Slab . . . . . . . 80

Hydrostatic Equilibration . . . . . . . $\quad$. 81

Safety Interlock, Level, and Drain _ . . . 81

b. Vertical Two-Dimensional Slab Apparatus . . 81

c. Horizontal Slab Apparatus . . . . . . $\quad$. 83

2. Deaerator . . . . . . . . . . 84

3. Illuminator . . . . . . . . . . . 85

4. Overlayering and Sample Application . . . . . 85

5. Constant-Temperature Bath and Circulator . . . 86 
6. Gel-Removing Tools . . . . . . . . . 87

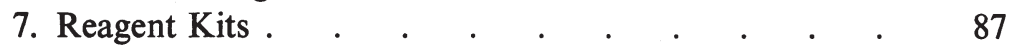

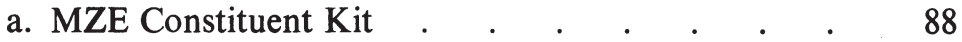

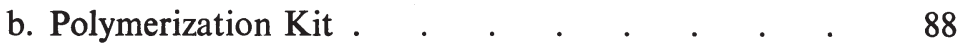

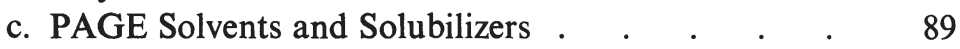

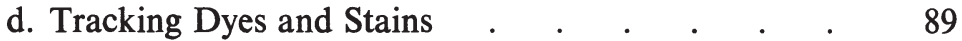

e. Molecular Size Standards for PAGE . . . . $\quad$. 90

f. Prefabricated, Storable Gel Kit . . . . . . . . 91

g. Isoelectric Focusing in Polyacrylamide Gel (IFPA) Kit . . . . . . . . . . . 91

h. Spacer Kit for Isotachophoresis . . . . . . $\quad$. 92

8. Pore Gradient Gel Electrophoresis . . . . . . 92

a. Apparatus . . . . . . . . . . . . . . $\quad$. 93

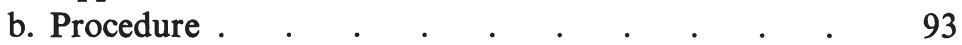

9. Apparatus for Determination of Polymerization Efficiency . . . . . . . . . . . . . 94

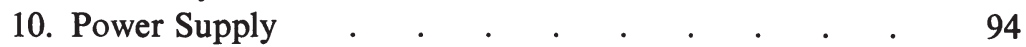

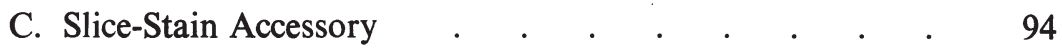

1. Vials and Test Tubes .

2. Destainer . . . . . . . . . . . 95

3. Transverse Gel Slicer . . . . . . . . . $\quad$. 96

4. Longitudinal Gel Slicer . . . . . . . . $\quad$. 98

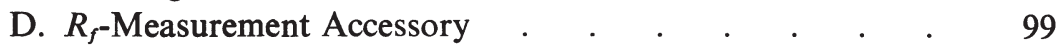

1. Procedure of Staining and $R_{f}$ Measurement . $\quad$. $\quad$. 100

2. Procedure of Electronic $R_{f}$ Measurement . . . 101

3. Densitometry . . . . . . . . . . 101

4. Autoradiography . . . . . . . . . . . 102

E. Computer Programs for Analysis of PAGE Data (PAGEPACK) . . . . . . . . . . . 104

F. Band Dispersion Measurement . . . . . . 105

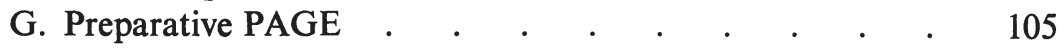

1. Extraction of Protein from Gel Slices . . . . 106

2. Milligram-Preparative Elution PAGE . . . . 106

a. Apparatus . . . . . . . . . . . . 106

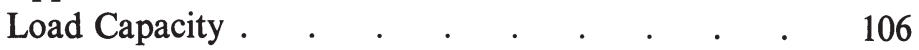

Geometric Restrictions . . . . . . . 108

Design of the Elution Chamber . . . . . 109

Temperature Control . . . . . . . . . . . 110

Electrical Field Symmetry . . . . . . . . 111

Wall Adherence . . . . . . . . . . . 111

Hydrostatic Equilibration . . . . . . . 111

b. Procedural Parameters of Preparative Elution PAGE 112 


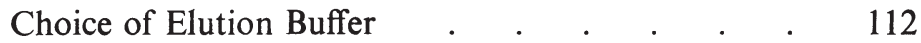

Choice of Elution Buffer Flow Rate . . . . 113

Choice of Gel and Gel Volume . . . . . . . 114

Choice of Current Density . . . . . . . . . . 114

Concentration Method . . . . . . . 114

Eluate Analysis . . . . . . . . . . 115

Eluate Analysis by Analytical PAGE . . . . 115

Procedure of Eluate Analysis by "Fused Rocket" Immunoelectrophoresis . . . . . . 116

Impurities . . . . . . . . . . . . . 116

3. Microgram-Preparative Elution PAGE . . . . 117

4. Isotachophoresis in Polyacrylamide Gel . . . . 117

5. Continuous-Flow Apparatus . . . . . . . . 118

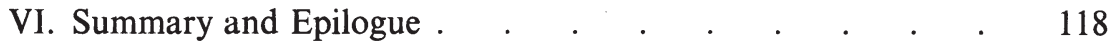

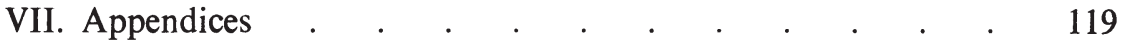

A. The Meaning of Homogeneity . . . . . . . 119

B. Forms of Charge Fractionation . . . . . . 120

C. Representative MZE Buffer Systems . . . . . 121

D. Purification of the Reactants of the Polymerization Reaction . . . . . . . . . . . 138

E. Activity Assay on Analytical Gels . . . . . 138

F. Glossary of Terms . . . . . . . . . . . 139

VIII. References . . . . . . . . . . . . 141

\section{Chapter 3}

Estimation of Molecular Weight by Gel Filtration and Gel Electrophoresis. I. Mathematical Principles

David Rodbard

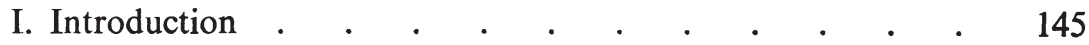

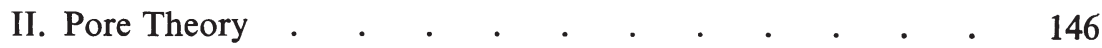

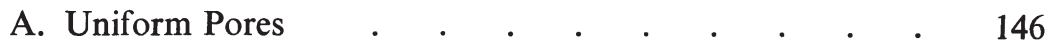

B. Distribution of Pore Sizes . . . . . . . . 148

III. Estimation of Molecular Weight Based on the Ogston Model 160

A. Gel Filtration . . . . . . . . . . 160

B. Polyacrylamide Gel Electrophoresis . . . . . 163

C. SDS-PAGE . . . . . . . . . . . 166

D. Other Methods Based on the Ogston Model . . $\quad 170$

E. Relationship to Other Physicochemical Methods . . 172

IV. Concluding Remarks . . . . . . . . . . . . 174

V. Appendix . . . . . . . . . . . . . . . . . . 176

VI. References . . . . . . . . . . . . 178 


\section{Chapter 4}

Estimation of Molecular Weight by Gel Filtration and Gel Electrophoresis. II. Statistical and Computational Considerations

David Rodbard

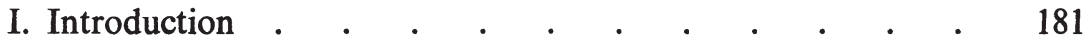

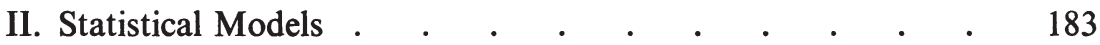

A. Model I: Relationship between $R_{f}$ and Molecular Weight 185

B. Model II: $\log \left(R_{f}\right)$ vs. MW . . . . . . . . $\quad . \quad 194$

C. Model UI: Sigmoidal Relationship between $R_{f}$ (or $K_{\text {av }}$ )

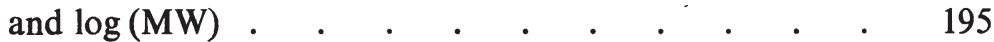

D. Comparison of Models I-III . . . . . . . 199

E. Model IV: The Ogston Model . . . . . . 200

III. Discussion . . . . . . . . . . . . 206

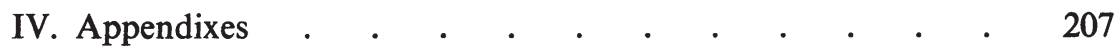

A. Detection of Outliers . . . . . . . . 207

B. Testing Goodness of Fit . . . . . . . . 208

C. Relationship between Number of Standard Proteins and Size of Confidence Limits $\quad$. $\quad . \quad$. $\quad . \quad$. $\quad . \quad$. 210

D. Confidence Limits for a Line . . . . . . . 211

E. A BASIC Program for Weighted Nonlinear Least-Squares Curve Fitting . . . . . . . . . . . 213

F. Weighting for the Logit, Probit, or $\operatorname{erfc}^{-1}$ Functions . 214

G. Glossary of Terms . . . . . . . . . 215

V. References . . . . . . . . . . . . 217

Chapter 5

Zone Electrophoresis, Isoelectric Focusing, and Displacement Electrophoresis (Isotachophoresis) in Carrier-Free Solution

\section{Stellan Hjertén}

I. Introduction: A Comparison between Electrophoresis in Free Solution and in the Presence of Supporting Media . . . 219

II. Zone Stabilization by Rotation of the Electrophoresis Tube . 220

III. A Short Description of the Electrophoresis Equipment . $\quad 222$

IV. The Application Range for the Equipment for Carrier-Free Electrophoresis . . . . . . . . . . 223

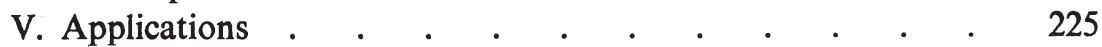

A. Zone Electrophoresis . . . . . . . . 225

B. Isoelectric Focusing . . . . . . . . . 227 
C. Displacement Electrophoresis . . . . . . 228

VI. References . . . . . . . . . . . . 231

\section{Chapter 6}

Hydrophobic Interaction Chromatography of Proteins on Neutral Adsorbents

Stellan Hjertén

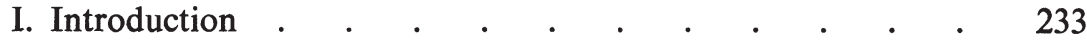

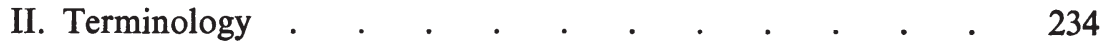

III. Concept of Hydrophobic Interaction . . . . . . $\quad$. 234

IV. Method for Coupling of Alkyl or Aryl Groups to Agarose . 238

A. Displacement of Water from the Agarose Gel by Dioxane 238

B. Coupling of Glycidyl Ethers to Agarose . . . . 238

C. Displacement of Dioxane from the Agarose Gel by Water 239

V. Adsorption and Desorption Parameters . . . . . 239

VI. Enzyme Reactors . . . . . . . . . . 241

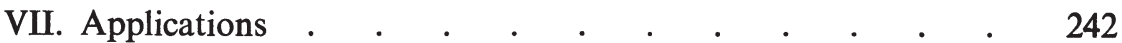

A. Hydrophobic Interaction Chromatography of Plasma Proteins . . . . . . . . . . . 242

B. Hydrophobic Interaction Chromatography of Membrane Proteins

VIII. References

\section{Chapter 7}

\section{Hydrophobic Adsorption Chromatography of Proteins}

B. H. J. Hofstee

I. Introduction . . . . . . . . . . . . 245

II. General Background . . . . . . . . . 247

A. Hydrophobic vs. Electrostatic Interaction . . . . 247

B. Apparent Irreversibility and Inhomogeneity of Protein Binding . . . . . . . . . . . . . 251

C. Nonspecific vs. Specific Binding . . . . . . 254

D. Nonspecific Protein Binding in Biospecific Adsorption (Affinity) Chromatography . . . . . . . . 255

III. Hydrophobic (Nonionic) Adsorption Chromatography . . 259

A. Accessibility of Hydrophobic Groups of Native Proteins . 259

B. Factors Affecting Hydrophobic Adsorption . . . 262 
C. Adsorbents • .

D. Chromatographic Procedures . . . . . . 268

E. Separation of Protein Mixtures . . . . . . 270

IV. References . • • . . . . . . . . 275

Chapter 8

Sievorptive Chromatography: Powerful Procedures for Rapid Enzyme Purification

Leslie H. Kirkegaard

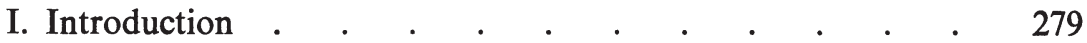

A. Importance of Multistage Equilibrium Procedures . . 280

B. Relationship of Sievorptive Chromatography to Classical Procedures . . . . . . . . . . . 282

II. Ion Filtration Chromatography . $\quad$. $\quad$. $\quad . \quad$. $\quad$. $\quad 284$

A. Principles of Separation . $\quad . \quad$. $\quad . \quad$. $\quad . \quad$. $\quad . \quad 284$

B. Technique of Ion Filtration Chromatography . . . 290

III. Intervent Dilution Chromatography . . . . . . 292

A. Concept of Intervent Dilution Chromatography . . 293

B. Technique of Intervent Dilution Chromatography . . 297

C. Separation of Ribosomal Proteins from rRNA . . . 299

IV. Gradient Sievorptive Chromatography . . . . . 302

A. Concept of Gradient Sievorptive Chromatography . . 303

B. Technique of Gradient Sievorptive Chromatography . 310

C. Examples of Gradient Sievorptive Chromatography . 312

V. Use of Sievorptive Chromatography in Enzyme Purification . 316

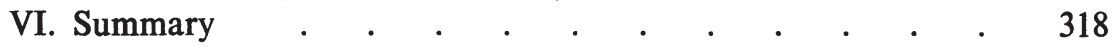

VII. References . . . . . . . . . . . . 318

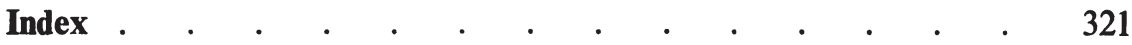




\section{CONTENTS of Volume 1}

Chapter 1

Sedimentation and Gel-Permeation Chromatography of Associating-Dissociating Macromolecules:

The Role of Ligand Mediation and Rates of Reaction

John R. Cann

Chapter 2

Trans Electrophoresis

Nicholas Catsimpoolas

Chapter 3

Immunodiffusion

Alfred J. Crowle

Chapter 4

Isoelectric Focusing in Polyacrylamide Gel

James W. Drysdale

Chapter 5

Purification of Chemically Modified Proteins

Robert E. Feeney and David T. Osuga

Chapter 6

Chromatographic Peak Shape Analysis

Eli Grushka 
xviii

Chapter 7

Sedimentation Equilibrium of Proteins in Density Gradients

James B. Ifft

Chapter 8

Hollow-Fiber Separation Devices and Processes

Burton A. Zabin

Chapter 9

Affinity Chromatography, Principles and Applications

Indu Parikh and Pedro Cuatrecasas 